OPEN ACCESS

Edited by:

Tara Ratnam,

Independent Researcher,

Mysore, India

Reviewed by:

Edward R. Howe,

Thompson Rivers University, Canada

Joseph Samuel Backman,

Alpine School District, United States

*Correspondence:

Mary Elizabeth Dotson

libby.dotson@duke.edu

Specialty section:

This article was submitted to

Teacher Education,

a section of the journal

Frontiers in Education

Received: 30 September 2019 Accepted: 28 January 2020

Published: 25 February 2020

Citation:

Dotson ME, Alvarez V, Tackett M Asturias G, Leon I and Ramanujam N (2020) Design Thinking-Based STEM

Learning: Preliminary Results on

Achieving Scale and Sustainability

Through the IGNITE Model.

Front. Educ. 5:14.

doi: 10.3389/feduc.2020.00014

\section{Design Thinking-Based STEM Learning: Preliminary Results on Achieving Scale and Sustainability Through the IGNITE Model}

\author{
Mary Elizabeth Dotson ${ }^{1,2 *}$, Valentina Alvarez ${ }^{1}$, Maria Tackett ${ }^{3}$, Gabriela Asturias ${ }^{4,5}$, \\ Isabela Leon ${ }^{2}$ and Nirmala Ramanujam ${ }^{1,2,5}$
}

${ }^{1}$ Department of Global Health, Duke University, Durham, NC, United States, ${ }^{2}$ Department of Biomedical Engineering, Duke University, Durham, NC, United States, ${ }^{3}$ Department of Statistical Science, Duke University, Durham, NC, United States, ${ }^{4}$ Fundación Desarrolla Guatemala para la Educación y Salud (FUNDEGUA), Guatemala City, Guatemala, ${ }^{5}$ Center for Global Women's Health Technologies, Duke University, Durham, NC, United States

Solutions to the most pressing global issues require creative innovators, critical thinkers, and problem-solvers. Yet rural communities globally often lack the resources to provide adequate STEM design-thinking coursework at the primary and secondary school level. Ignite is a novel approach to STEM curricula, providing a framework that addresses this disparity by using design thinking. Students are empowered to understand the sustainable development goals (SDGs) through the development of technological solutions to community or health problems; problems they may relate to or directly experience. Each Ignite curriculum follows a basic formula: (1) students learn a specific set of engineering skills, (2) students work in teams to use the human-centered design process, and (3) they develop a solution to a (SDG) using the engineering skills they learned. Ignite began with just four undergraduate students who participated in a design-thinking biomedical engineering course taught at Duke University. Through evidence-based peer-led co-learning model, 79 additional students from Guatemala and the U.S. have become trainers and have taught more than 1,500 students across 16 schools in Guatemala since 2017 with preliminary data suggesting the program has a positive impact on student perceptions of STEM in the inaugural school where Ignite was launched, Instituto Indigena Nuestra Senora del Socorro (IINSS). Preliminary data suggests that this program is both scalable and sustainable due to its peer-led, student learning model and due to a local partner, FUNDEGUA, who is managing the implementation of Ignite locally in Guatemala.

Keywords: STEM - science technology engineering mathematics, design-thinking methodology, co-learning, LMIC, sustainable development goals - SDG

\section{INTRODUCTION}

Access to quality education in STEM is linked to reduced poverty, economic growth, and more resilient democracies; these disciplines play an essential role in addressing many of the Sustainable Development Goals (SDGs). International organizations, such as USAID and UNESCO have moved STEM education to the forefront of their institutional goals as careers in STEM fields are 
projected to see exponential growth in the twenty-first century (UNESCO, 2017). Creation of sustainable and scalable programs to address disparities in access to STEM education continues to be a challenge. Programs implemented by international nonprofits and think tanks often lack the resources to scale the number of teachers they can provide to any given program (Elayah, 2016). Additionally, the pedagogical methods used can be inappropriate for the specific context and culture for which they are intended. An example of this is the importation of foreign instructor labor which not only results in limited input by the intended beneficiaries (Waisbord, 2008) and little interest from the target population, but also fails to build local educational workforce capacity. To ensure students benefit sustainably and equitably from programs originally designed by foreign institutions, educators should pivot and focus on building workforce capacity and independence within these communities. To accomplish this, it is essential that educators work with the community and not "for" it. The co-learning framework and peer-led learning are two ways that Ignite aims to improve the sustainability and scalability of STEM coursework in communities where this type of education is absent.

\section{PEDAGOGICAL FRAMEWORK}

Critical Pedagogy, also known as co-learning, experimental, cooperative, and/or collaborative learning, is a methodology where students and teachers create a collaborative learning environment. This cultivates a learning atmosphere of empathy and mutual understanding between teacher and student (Mayo, 1995; Freire, 2000). The teacher assumes that he or she will learn just as much from the students as the students learn from the teacher. Students are empowered as experts on the issues they face daily and those issues are used as a launchpad for rich classroom discussion. Co-learning is a form of active, dynamic learning in contrast to traditional, passive teaching formats, such as the standard lecture. Utilizing team-based learning, such as small group discussions and class-wide debates is integral to an active approach to education. Co-learning has been shown to improve critical thinking, enhance communication skills, and improve sociocultural awareness for both teachers and students (Baines et al., 2007). Research indicates that this method significantly increases student performance (Scager et al., 2016). It has been widely used within ESL (English as a Second Language) classrooms and adopted across subjects in undergraduate education programs with success for at least 20 years (Frye, 1999).

Co-learning is becoming more popular in universities and well-funded secondary schools. At one of the highest performing secondary schools in Hong Kong, co-learning is a mandatory part of the school's curriculum. This program places teachers in training within schools that have been identified as having a great

Abbreviations: SDG, Sustainable Development Goals; FUNDEGUA, Fundación Desarrolla Guatemala para la Educación y Salud or Development Foundation of Guatemala for Education and Health; STEM, Science, Technology, Engineering, and Math; PLTL, Peer Led Teacher Learning; SLT, Situated Learner Theory; HCD, Human-centered Design; IINSS, Instituto Indígena Nuestra Señora del Socorro. need for well-trained educators. This positions new teachers as both co-educators and co-learners, the latter allowing students to learn about a community that may be foreign to them. Teachers are trained to incorporate their students' experiential expertise into lesson plans, allowing students to share their personal experiences and developed understanding of their world. When surveyed, teachers felt more attentive to student needs and test scores significantly improved (Harfitt, 2018).

While co-learning emphasizes mutual respect between teacher and student, peer-led team learning (PLTL) can build local capacity by increasing the educational workforce informally. The "teacher" in PLTL is a student (or peer) who has successfully trained on how to facilitate small group learning on a specific topic (Quitadamo et al., 2009). One research university implemented PLTL in undergraduate science and math courses. They found that under-performing students improved their ability to identify and critically analyze problems and female students improved their test scores more frequently than their male counterparts (Quitadamo et al., 2009). PLTL programs also improve student retention in STEM fields at the undergraduate level, as well as improve student perceptions of STEM careers (Bowling et al., 2015).

A meta-analysis of various PLTL programs revealed that it had a significant positive impact on the lifelong trajectory of student learning (Ruiza-Primo et al., 2011). Another metaanalysis revealed that students with this kind of learning experience had on average, a $16 \%$ increase in test scores (Quitadamo et al., 2009). A program called Near-Peer Education, focused on educating secondary level students, improved student engagement in STEM coursework. Students in the program indicated that they were encouraged by the ability to explore topics with young professionals closer to their age, and this effect was enhanced by the relatability of the learning experience (Tenenbaum et al., 2014).

Co-learning and the PLTL methodology are similar in the way they transform learning into a dynamic, active, and collaborative experience. Both focus on placing the learner and their unique experiences at the center of the curriculum, choosing topics and modules based on those experiences. While such methods have been widely implemented at the collegiate level over the last 30 years-with a century of theoretical inquiry supporting this endeavor-they have rarely been implemented at the primary and secondary level. This is a unique opportunity to make high-quality STEM education more accessible to low and middle-income communities. Furthermore, few studies have described the impact of PLTL and co-learning programs on peer educators themselves.

Can we mobilize the demonstrable power of peer-led colearning for elementary, middle and high school students? Can we do this in communities where there is a lack of design thinking- based STEM education? Can we make this innovative program both sustainable and scalable? This is the premise for Ignite, a design thinking-based STEM curriculum focused on the Sustainable Development Goals (SDGs). Ignite relies on peer-to-peer collaborative learning, in which trained studentinstructors teach STEM concepts to peers in low-resource communities. This paper evaluates preliminary data on the 
impact of this model on trainers and trainees and includes a preliminary assessment of the impact on students in Guatemala from 2017 to 2019.

\section{LEARNING MODEL}

Ignite is a design thinking program that focuses on addressing one SDG per module, using STEM concepts. The framework for this model has been published previously (Mueller et al., 2019). The core aspects of the program include: (1) the ability to define a problem based on a community and/or health need that the student can relate to, (2) ability to create solutions to those challenges using technology, and (3) being able to create a virtuous cycle through peer-to-peer instruction and team-based activities. The program structure is based on the concept of human-centered design (HCD) and can be completed in as little as 2 days and as many as 8 weeks depending on frequency of class time and chosen course structure (i.e., afterschool program, monthly workshop, etc.). Ignite was started at Duke University and is now sustained by the FUNDEGUA Foundation in Guatemala (one of Duke's key partner sites). The co-founder of this organization, Gabriela Asturias, participated in a course at Duke University in 2017, which offered an early form of the Ignite curriculum to university students studying global health and/or biomedical engineering. She then worked with three other students to adopt the curriculum for primary and secondary education in her home country, Guatemala. Together they implemented the program for the first time in the summer of 2017. Since then, FUNDEGUA has continuously iterated the curriculum based on feedback from educators and students in participating schools.

Ignite students work through the 5-stages of HCD: (1) empathize, (2) define a problem, (3) ideate and brainstorm solutions, (4) prototype, and (5) field test with feedback (IDEO) (Figure 1). This model is designed to improve critical thinking and creative problem-solving skills, in addition to the engineering skills needed to bring an idea from sketch to prototype. During the "empathize" and "define" phases, students engage directly with their peers to understand local community needs regarding a challenge directly related to the SDGs. Alternatively, the model can leverage student's specific knowledge of their local communities to engage them in STEM activities (co-learning). In the "ideate" and "prototype" phases, students work in teams to brainstorm solutions and to use feedback to iterate on their designs. Students then present a design matrix, describe resource constraints, and receive feedback from peers.

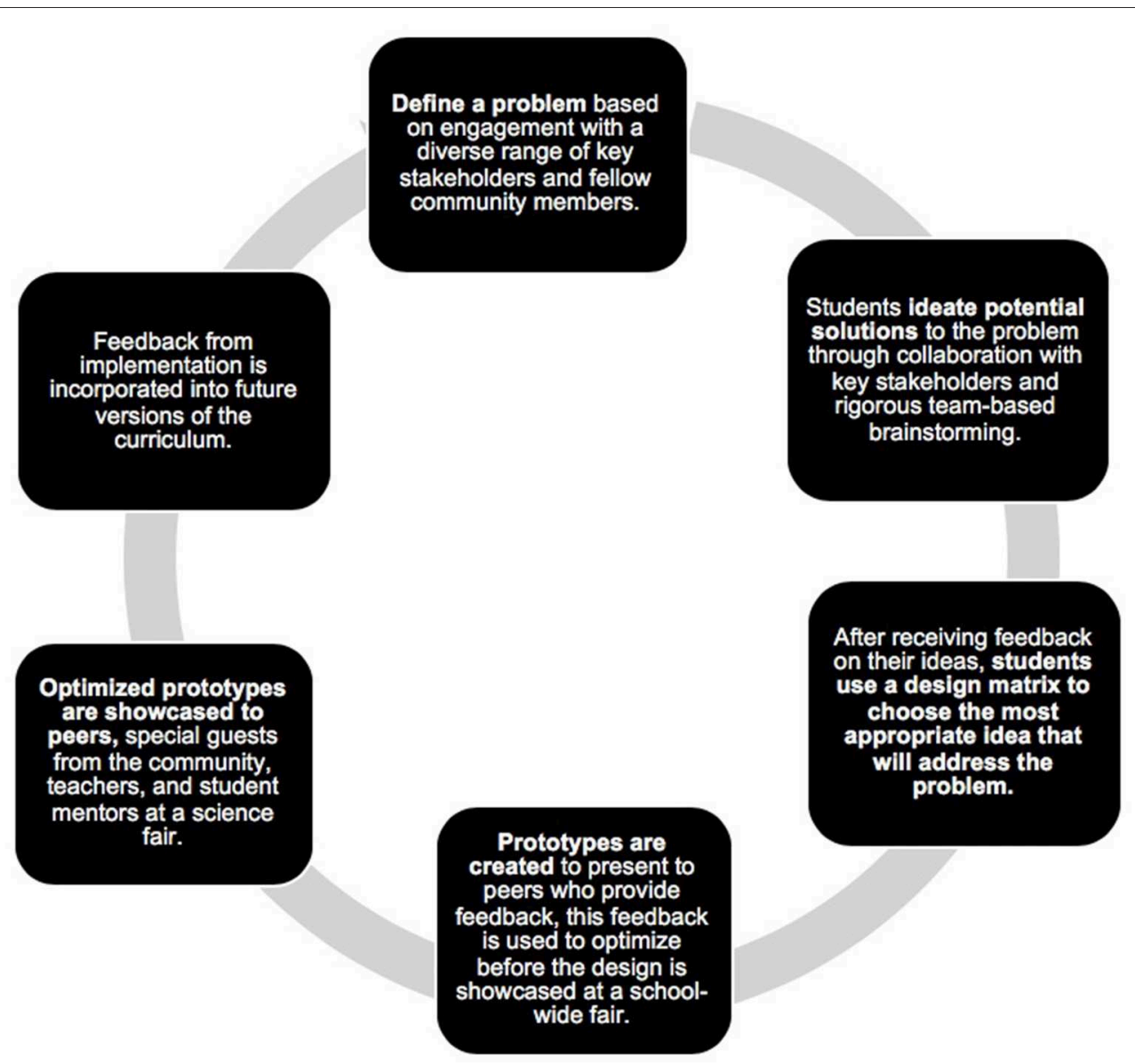

FIGURE 1 | The circular feedback loop of the Ignite model. 
After this presentation, there is typically a short Q\&A where panel members, including teachers and business owners from the community, ask questions to give additional feedback. In the "deliver" phase, students present their prototype to the school and special guests, like a science fair. In the past, students have continued their projects beyond the formal conclusion of Ignite and have tested their solutions as well as continued to iterate their prototypes and sold them. The current Ignite curriculum does not include a formal mechanism for field testing, rather, it empowers students to begin this cycle of design. The cycle begins again when former instructors train their former students to become new instructors and trainers for a new cohort of Ignite learners. So far, trainers from Emory University, the University of Michigan, the American School of Guatemala, Universidad de Valle de Guatemala and the NGO Asociación Amigos del Lago de Atitlán have participated as both students and trainers.

\section{The Evolution of the Ignite Model in Guatemala}

In the Spring of 2017, Duke University students participated in the course BME 290-Global Women's Health Technologies, which offered the Ignite curriculum. This course required that students work and empathize with an international community to define a community challenge associated with one of the SDGs. The inaugural challenge was energy poverty (SDG \#7). This selection was due to the elevated number of low resource communities in Guatemala impacted by a lack of access to lighting at night. Students were tasked with ideating potential solutions, and rapidly prototyping a design with significant feedback from their peers. Following conclusion of the course, three students applied for funding opportunities to develop and implement an Ignite curriculum in Guatemala. Prior to arriving in the field, the curriculum was developed at Duke University. In the summer of 2017 , student trainers traveled to Guatemala and taught the curriculum to 79 female students in grades 10 through 12 for 8 weeks at the Instituto Indígena Nuestra Señora del Socorro (IINSS). Additionally, 20 male and female 11th-12th grade students underwent a 1-day workshop at the Instituto Mixto Intercultural Santiago and three female university students participated in another 1-day workshop at the Universidad Francisco Marroquín. Following the summer 2017 initial implementation, FUNDEGUA adopted the curriculum and continued to iterate locally.

In 2018 a follow-up curriculum on water contamination (SDG \#6) was developed by another cohort of Duke students. This topic was chosen because IINSS sits on the second largest lake in the country of Guatemala, Lake Atitlán, which is an important source of income for the region, yet heavily polluted. Duke students from the prior summer served as trainers to two new student-trainers for 12 weeks to develop the curriculum with input from FUNDEGUA and IINSS. This involved participation in the BME 290 course and weekly meetings to co-develop the curriculum with the new trainers. In the summer of 2018, the newly trained Dukes students and one Guatemalan traineeturned-trainer taught the light and water curricula to 79 middle and high-school students from 7th, 8th, 9th, and 11th grade,
35 who participated the year before were taught the water curriculum and 44 new students learned the light curriculum. The trainer from Guatemala who worked with IINSS was taught by the two Duke students. In 2019, two additional Duke trainers taught 41 students from 7 th to 9 th grade the water curriculum only at IINSS (4-week course).

To ensure program sustainability FUNDEGUA had one staff member learn the curriculum independently via online resources in 2018. This staff member independently worked to train students from Emory University (4 students), the University of Michigan (12 students), the Universidad de Valle de Guatemala (13 students), the American School of Guatemala (6 students), and the NGO Asociación Amigos del Lago de Atitlán (22 staff). Concurrently, FUNDEGUA worked with partner schools across Guatemala to optimize the curricula and evaluation metrics based on teacher and student input. Partner schools were chosen through a two-step process. First, a representative from FUNDEGUA interviewed he school principal. Second, they conducted focus groups with teachers and students. The goal of each step was to introduce the Ignite model while assessing school-wide interest and community level buy-in to establish if Ignite would be a good fit.

\section{RESULTS}

Ignite in Guatemala began in the Instituto Indígena Nuestra Señora del Socorro (IINSS) in Sololá. An early assessment of impact of Ignite on these students is presented later in the results section. Through the train-the-trainer method, FUNDEGUA has now implemented Ignite in 16 different schools across six municipalities in Guatemala: Barberena, Mixco, San Andrés Semetabaj, San Lucas Tolimán, Antigua Guatemala, and Guatemala City. Two of these schools participated in IGNITE for two consecutive years and one for three. Starting with just four Duke trainers and 79 Guatemalan students in the first cohort in 2017, 76 additional trainers have learned the Ignite curriculum since the first cohort in 2017, and they have collectively reached over 1,500 additional students across Guatemala, the majority of which were female (Figure 2). Overall, the majority of trainers (69) majored in STEM and many studied engineering specifically at the university level (30). All trainers were between the ages of 17 and 23 at the time of Ignite implementation.

\section{Scaling the Program in Guatemala Through the Train-the-Trainer Model}

The exact methodology by which instructors were trained evolved organically through 10 different cohorts from 2017 to 2019: eight from Duke University, one FUNDEGUA staff member, 25 from the University of Michigan, four from Emory University, 13 from el Universidad del Valle de Guatemala, six from the American High School of Guatemala and 22 from the non-profit Amigos del Lago. Each Duke cohort trained the following Duke cohorts (2017 taught 2018, and 2018 taught 2019). The Duke cohort from 2017 trained the Guatemalan trainee that participated in the 2018 Duke cohort, as well as the first University of Michigan cohort (2018). The other 


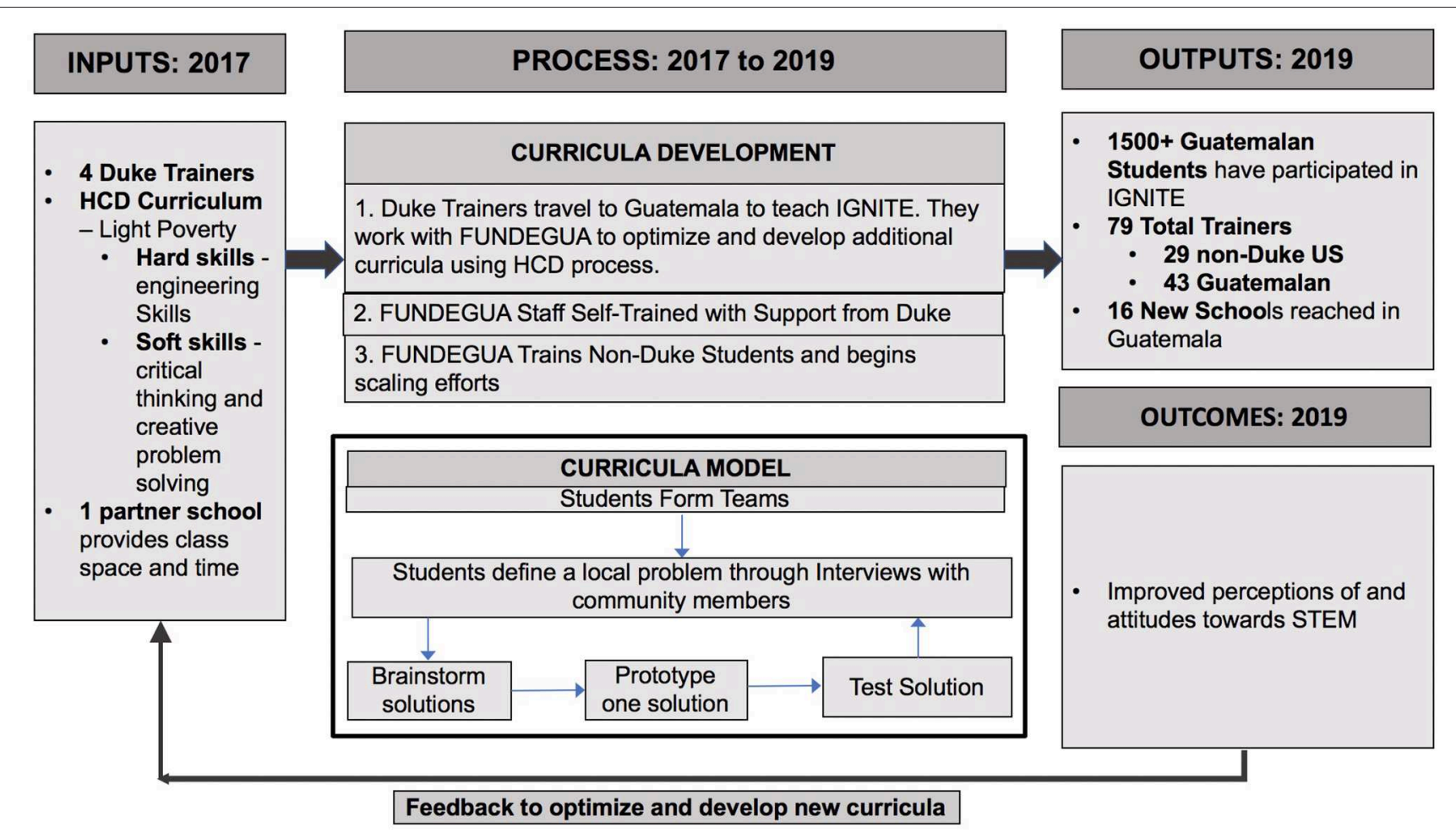

FIGURE 2 | Evolution of Ignite (Duke-FUNDEGUA Collaboration) in Sololá, Guatemala, 2017-2019.

trainees were trained by FUNDEGUA staff either in-person or through online video calls or with comprehensive resources for self-study. All training methods were adapted from the activities and readings available to students in BME 290 at Duke University, where Ignite originated. The training model was adjusted for the specific needs and time constraints of each new cohort. Two unique training approaches were used. In the first approach, instructors were trained through in-person workshops hosted by former Ignite instructors with supplemental readings to reinforce the learning objectives. In the second approach, training was conducted online via Skype, supplemental readings, and videos from open-source education platforms. FUNDEGUA reports that $67.1 \%$ of all trainers learned through in-person workshops, $31.6 \%$ learned through online methods, and $1.3 \%$ taught themselves independently. The Duke cohorts learned in-person by enrolling in the BME 290 course and peer-topeer instruction from former Ignite trainers at Duke. The Universidad del Valle de Guatemala, American High School of Guatemala, non-profit Amigos del Lago and Emory University cohorts learned in-person and received supplemental materials to reinforce learning. The University of Michigan cohorts learned through online methods.

To begin iterating a sustainable evaluation strategy of the efficacy of each training method, FUNDEGUA started to implement and gather feedback on a pre- and post-knowledge acquisition test for the cohorts in the Summer of 2019 of the non-profit Amigos del Lago $(n=22)$ and American School of Guatemala $(n=6)$. It is important to note that these groups completed in-person workshop training and received supplementary material to reinforce learning. FUNDEGUA staff assessed knowledge acquisition in-person during the sessions before moving to the next learning objective. Activities related to the material taught were completed using Google Forms between training sessions. Lastly, a pre- and post-knowledge acquisition test was shared using the Qualtrics platform, to assess acceptability and ease of use. For this test, trainees were asked to solve a series of STEM knowledge, human-centered design and critical thinking problems upon completion of the workshops. The survey also included questions on best practices for important safety measures. The goal of testing an evaluation strategy was to determine the most effective measure to ensure the foundational knowledge and skills were acquired, making sure the trainees were prepared to replicate Ignite. FUNDEGUA staff determined that administering a pre- and post-knowledge acquisition test is important to ensure a baseline is achieved. They also found that including activities after each session is necessary to understand if reinforcement of key foundational topics needs to be delivered before the training is complete.

\section{Impact on Trainers}

Anecdotal evidence reported by FUNDEGUA staff suggests that many of the trainers remained involved in some aspect of Ignite after initial implementation. Several indicated that they trained other cohorts of Ignite instructors, with Emory students formalizing their participation through the creation of a university-sponsored Ignite club and University of Michigan 


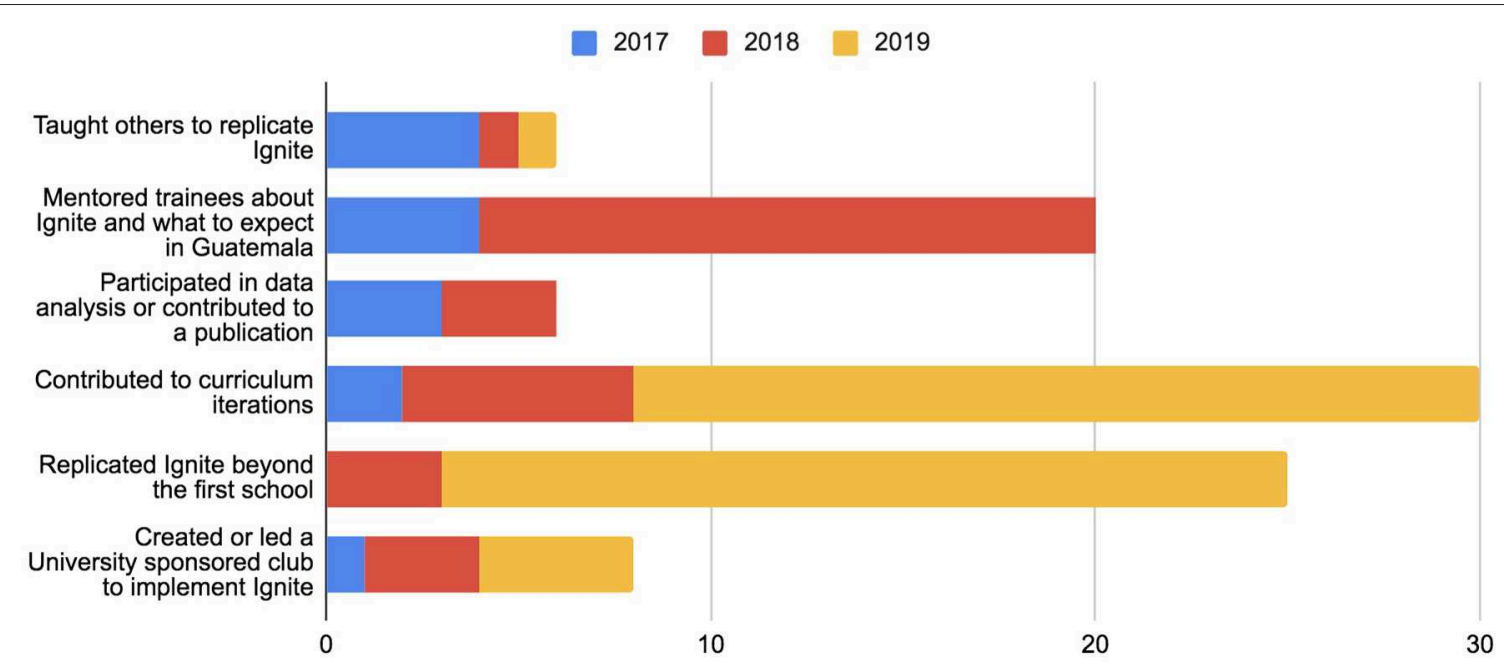

FIGURE 3 | Continued involvement in Ignite beyond initial participation from 2017 to 2019 . Some Ignite trainers were involved in Ignite after their first implementation in more than one way, thus the numbers don't reflect the total trainers of Ignite from 2017 to 2019 which was 79.

students making Ignite in Guatemala their annual engineering service-learning activity. The various ways in which trainers stayed involved is summarized in Figure 3. The 2019 cohorts have not been included as mentoring or training other students because the training for 2020 implementation had not started at the time of publication of this paper. Club leads and FUNDEGUA staff have reported on trainer involvement beyond initial implementation, which are summarized in Figure 3. Several students remained involved in research and development, participating in aspects of the program, such as data analysis. Among those who did not remain directly involved in Ignite, at least one trainer indicated that they remained in contact with their students via social media. Some trainers told FUNDEGUA staff that Ignite positively impacted their courses, extracurricular activities, career and/or graduate school choice. Several trainers indicated that Ignite inspired them to pursue coursework in education and/or extracurricular activities. It is interesting to note that Guatemalan trainers were more involved in iterating the curriculum for new contexts, while US trainers remained more involved in mentoring new trainers.

To obtain a more nuanced understanding of the impact of Ignite's training method on instructors, in-depth interviews were conducted with four Ignite trainer representatives, one from each of four different Universities across the U.S. and Guatemala (Duke University, the University of Michigan, Emory University and Universidad del Valle de Guatemala). All interviews were approved through Duke University's International Review Board [IRB\#2017-0507], and participants were asked permission to disclose the name of the university which they attend. Participants were asked broad questions related to how they became involved in Ignite, how they were trained, what they most enjoyed, and how it had impacted their life afterwards (see Appendix 1). The audio-recordings were transcribed twice by two different researchers and then coded for themes using a Grounded Theory approach, which facilitates the emergence of patterns in qualitative data analysis (Martin and Turner, 1986). Overlapping themes were discussed between the researchers to decide on the final outcome of the study. It is of importance to note that of the 13 questions asked, only four questions were answered by all participants (Table $\mathbf{1}$ ).

These four questions revealed the strengths of the Ignite model as detailed in Table 1. First, all trainers faced unexpected challenges in the field that they were able to overcome seemingly from the open-endedness of the Ignite model. Second, most trainers indicated that the freedom to iterate on the curriculum based on student input and feedback from other trainers was a positive aspect of the program. Approximately $40 \%$ of trainers modified the Ignite curriculum during their instruction and $15 \%$ continued to be engaged in Ignite or a related program. Third, half of the trainers discussed the importance of human-centered design and how they believed it impacted their teaching style and student interest. Finally, trainers stayed involved with Ignite or participated in a similar research project even after they had completed their initial program. In particular, one trainer from Emory stated that he started an Ignite club at his University where they have continued iterating on the curriculum and working with FUNDEGUA closely to send multiple cohorts of students to Guatemala each year.

\section{Impact on Student Perceptions of STEM}

Pre- and post-implementation surveys were distributed at IINNS in the $2018(n=64)$ and $2019(n=38)$ cohorts to understand how participation in Ignite might have shifted student attitudes toward STEM. The surveys were designed using the Knowledge, Attitudes, and Practices (KAP) methodology. Several questions on inclinations to contribute to their communities were included for the benefit of the implementers though they are not included as part of the STEM positivity analysis. The pre- and post- survey distributed was exactly the same and included 
TABLE 1 | Emergent themes from in-depth trainer interviews.

\begin{tabular}{|c|c|c|c|c|}
\hline Institution & Duke U & Emory U & $\begin{array}{l}\text { Universidad del Valle de } \\
\text { Guatemala }\end{array}$ & University of Michigan \\
\hline Grades taught & 7th-9th, 11th & 7th-9th & 7th-10th & 10th-11th \\
\hline \multirow[t]{2}{*}{ Gender and Intended Major } & Female & Male & Female & Male \\
\hline & Global Health & Health Sciences/Pre-med & Engineering & Engineering \\
\hline $\begin{array}{l}\text { Did you face any } \\
\text { unexpected challenges } \\
\text { implementing lgnite } \\
\text { curriculum? }\end{array}$ & $\begin{array}{l}\text { The students knew little about } \\
\text { adding and subtracting } \\
\text { fractions, a huge part of the } \\
\text { curriculum. We had to slow the } \\
\text { curriculum down }\end{array}$ & $\begin{array}{l}\text { Students wanted to learn more } \\
\text { than the curriculum we had, so } \\
\text { we improvised by adding new } \\
\text { modules, such as one on local } \\
\text { plant biology }\end{array}$ & $\begin{array}{l}\text { Our team realized we needed to } \\
\text { teach students basic math } \\
\text { skills, students who were in } \\
\text { 11th grade }\end{array}$ & $\begin{array}{l}\text { Difficult for the school to find } \\
\text { class time for us to teach, we } \\
\text { modified the curriculum so it } \\
\text { would be shorter }\end{array}$ \\
\hline $\begin{array}{l}\text { Did you iterate on the lgnite } \\
\text { curriculum while in the field? }\end{array}$ & $\begin{array}{l}\text { Yep, had to add additional } \\
\text { classes on fractions }\end{array}$ & $\begin{array}{l}\text { Once the students finished and } \\
\text { were bored, we added new } \\
\text { classes on different topics like } \\
\text { motors }\end{array}$ & $\begin{array}{l}\text { Very little, we adjusted the } \\
\text { Spanish to ensure it was } \\
\text { appropriate for the context } \\
\text { [Guatemala] }\end{array}$ & $\begin{array}{l}\text { Had to add several more } \\
\text { teaching sessions to help } \\
\text { students with basic math skills to } \\
\text { complete Ignite }\end{array}$ \\
\hline $\begin{array}{l}\text { What role do you believe } \\
\text { human centered design play } \\
\text { in the student engagement } \\
\text { and interest in the } \\
\text { curriculum? }\end{array}$ & $\begin{array}{l}\text { Students were way more } \\
\text { engaged and excited to be able } \\
\text { to use their own ideas in the } \\
\text { classroom setting through } \\
\text { design-thinking }\end{array}$ & $\begin{array}{l}\text { The students seemed... like they } \\
\text { had never been given the } \\
\text { freedom to explore their own } \\
\text { ideas in the way of } \\
\text { design-thinking }\end{array}$ & $\begin{array}{l}\text { I wish that this [human centered } \\
\text { design] had been taught in my } \\
\text { high school, it was cool seeing } \\
\text { the students take pride in their } \\
\text { ideas }\end{array}$ & $\begin{array}{l}\text { Students felt valued and heard, } \\
\text { very cool }\end{array}$ \\
\hline $\begin{array}{l}\text { Did you continue } \\
\text { participating in Ignite after } \\
\text { initial implementation? }\end{array}$ & $\begin{array}{l}\text { Only in developing evaluation } \\
\text { tools and analyzing data }\end{array}$ & $\begin{array}{l}\text { Started a club that is growing } \\
\text { really fast at Emory, sending } \\
\text { students every summer now }\end{array}$ & $\begin{array}{l}\text { Tried to recruit more students } \\
\text { from our university to teach }\end{array}$ & $\begin{array}{l}\text { Started small student group that } \\
\text { sends people to teach Ignite } \\
\text { each year }\end{array}$ \\
\hline
\end{tabular}

35 questions in total. Questions were broken down by subject area (see Appendix 2). For each subject, students answered questions, such as whether they would take math, science, or engineering and technology classes in the future, whether they would be interested to pursue a career in the subject, and how well they felt they performed in each subject as well as community outreach questions. Data was collected by a Duke Trainer with IRB approval [IRB\# 2017-0507] and no personal identifiable information was gathered other than grade level. The 2018 cohort taught 7 th, 8th, 9th, and 11th grade students. The 2019 cohort only taught 7 th, 8th, and 9th grade students. Only 64 of the 79 students from IINNS who participated in 2018 completed both the pre- and postsurvey, thus the sample size for that year is reported as such. In 2019, 41 students participated, but only 38 students completed the pre- and post- survey in full, thus the sample size for that year is reported as such. The survey responses from 2018 to 2019 were combined for the purposes of this analysis.

Students answered survey questions on a Likert scale with response options: (1) Not at All (2) No (3) Neutral (4) Yes (5) Absolutely. Their responses were quantified into levels of positivity toward STEM, where Not at All $=1$, No $=2$, Neutral $=3$, Yes $=4$, and Absolutely $=5$. The higher their score, the more positively they felt toward STEM. Their pre-survey responses were compared to their post-survey responses. Their responses were stratified by grade level. For each question in the survey (Math, Science, Engineering and Technology, and Community Contribution), all the scores (1-5) that the students recorded for the questions in a particular section (for instance, Math) were summed and divided by the total number of observations in the entire section. These results are shown in Table 2.

Statistical hypothesis testing and confidence intervals were used to evaluate if the differences in levels of positivity toward STEM before and after implementation was significant. To discern which grade had the greatest shift in attitudes, the results were stratified by grade level. To determine future steps for the program, the results were then evaluated by subject matter (math, science, engineering, and technology). Simulation-based inference methods were conducted, and the null hypothesis was that there would be no difference in the mean level of the student's positivity toward STEM before and after Ignite. The alternative hypothesis was that there is a difference (Table 2).

Including every grade level, the mean level of positivity toward STEM increased by 0.093 points after the implementation of Ignite, with $95 \%$ confidence interval of $0.031-0.155$, thus showing there was a statistically significant difference as seen in Table 2. Furthermore, when the results were stratified by grade level, students in 11th grade demonstrated the greatest difference in level of positivity toward STEM, on average, with an increase of 0.237 points ( $95 \%$ confidence interval of $0.133-0.340$ ). The other grades did not demonstrate statistically significant differences in mean overall levels of positivity toward STEM. However, when stratified by subject matter, 7 th grade students demonstrated a significant increase in levels of positivity toward Engineering and Technology. Furthermore, including all grade levels, students demonstrated a statistically significant increase in mean level of positivity toward Engineering and Technology of 0.137 points (95\% confidence interval of $0.049-0.225$ points). Lastly, there were small increases in the mean level of positivity toward math and science (see Appendix 3). 
TABLE 2 | Shifts in positive attitudes and perceptions of STEM.

\begin{tabular}{|c|c|c|c|c|c|}
\hline & $\mathbf{n}$ & Math & Science & Engineering and technology & Overall \\
\hline \multirow[t]{2}{*}{ 7th grade } & 16 & -0.199 & -0.151 & 0.293 & 0.023 \\
\hline & & $(-0.521,0.117)$ & $(-0.430,0.126)$ & $(0.070,0.514)^{*}$ & $(-0.135,0.182)$ \\
\hline \multirow[t]{2}{*}{8 th grade } & 21 & -0.122 & 0.048 & 0.074 & 0.024 \\
\hline & & $(-0.451,0.213)$ & $(-0.225,0.322)$ & $(-0.141,0.280)$ & $(-0.136,0.180)$ \\
\hline \multirow[t]{2}{*}{ 9th grade } & 36 & 0.058 & 0.06 & 0.015 & 0.041 \\
\hline & & $(-0.163,0.273)$ & $(-0.126,0.241)$ & $(-0.141,0.169)$ & $(-0.064,0.145)$ \\
\hline \multirow[t]{2}{*}{ 11th grade } & 29 & 0.338 & 0.153 & 0.23 & 0.237 \\
\hline & & $(0.115,0.565)^{\star}$ & $(-0.019,0.330)$ & $(0.083,0.378)^{\star}$ & $(0.133,0.340)^{\star}$ \\
\hline \multirow[t]{2}{*}{ All } & 102 & 0.067 & 0.05 & 0.137 & 0.093 \\
\hline & & $(-0.064,0.200)$ & $(-0.058,0.157)$ & $(0.049,0.225)^{*}$ & $(0.031,0.155)^{\star}$ \\
\hline
\end{tabular}

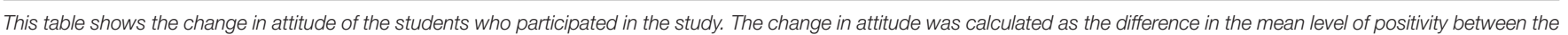

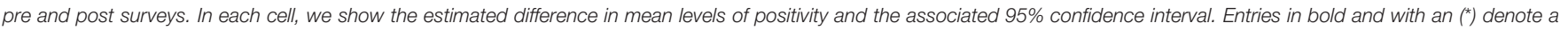
significant change in the pre and post positivity scores.

\section{DISCUSSION}

Ignite utilizes evidence-based learning methodologies, colearning, and peer-led teacher learning, to make design thinkingbased STEM coursework more appealing. It does so by anchoring these methods within a community-based problem that students face daily or in which students have a perceived interest. The program started with just four Ignite trainers and 79 students taught within one school. There are now 79 Ignite trainers and more than 1,500 students who have participated in the program across 16 schools in Guatemala. The peer-to-peer learning model is essential to scaling Ignite. In addition, peerto-peer learning benefits trainers and students alike in ways that might transform education and career trajectories. Just as the Near-Peer education program indicated that the increase in student scores was partly due to their ability to explore topics with young STEM professionals close to their age group (Tenenbaum et al., 2014). Ignite engages younger teachers who might have a more dynamic impact on students' academic trajectories. Moreover, the empowering nature of Ignite could foster an interest in STEM among students who might have access, but who would not participate otherwise. The high prevalence of university age student involvement could indicate that participating in Ignite is most appealing to students between the ages of 18 and 22, perhaps because students at this age are exploring different career paths and interests. The initial resources needed are minimal, further suggesting the program is sustainable through the peer-to-peer model. Although there were initial start-up costs to send trainers from a foreign university, we have demonstrated that the peer-to-peer training model allows local university and high school students to implement Ignite, making the program sustainable. Further, the significant increases in positive attitudes toward STEM amongst the students trained at IINSS indicate that highly motivated students could act as peer teachers and mentors of Ignite within their schools. This framework could allow for significantly more students to be exposed to design thinking-based STEM coursework than through traditional approaches. Although this study only discusses implementation in Guatemala from 2017 to 2019, Ignite has enormous potential beyond the efforts described. The HCD framework can be applied to any community need if the trainer has or can obtain knowledge of the specific topic at the center of that need.

It is important to note that all 79 trainers volunteered to participate in the Ignite program without compensation. Each cohort funded their own travel and materials cost through grants that all individuals applied for independently, without guidance from the program directors at Duke University. FUNDEGUA has received some compensation in the form of training stipends from select partner schools. The foundation reports that they have only received compensation from schools with the resources and willingness to do so, specifically schools who would like to compensate their team to help them to rapidly modify the curriculum for certain unique contexts. No one who participated received tangible monetary or vocational compensation for training or being trained, and no one paid any amount to receive the course and participants did not receive grades. Thus, it can be inferred that the follow-through seen by both trainers and students after the project ends in relation to the program's ability to empower and inspire action among participants. Additionally, the fact that many trainers remained engaged with Ignite suggests that it had a significant impact on them. This is consistent with other studies showing how peer led education can empower and impact the trainers just as much as the students (Badura et al., 2000). The various disciplines the trainers came from is another potentially important factor in the continued success of the Ignite learning model. This is because interdisciplinary peer-led teams at the undergraduate level have been shown to yield better learning outcomes than teams from a singular discipline, such as biomedical engineering (Carlson et al., 2016). As Figure 3 indicates, Guatemalan trainers remained more involved in iterating and creating new curricula for different contexts, while US trainers focused on mentoring new trainers. This could be attributed to the fact that Guatemalan trainers understand the culture and context of the partner schools in more depth, making it easier for them to identify weaknesses in the curriculum that should be addressed. Moreover, Figure 3 shows that over time more trainers became involved in iterating the 
curriculum, this points to the replicability of the model. Future studies should explore replicability to determine its significance.

There were stark differences in the composition of trainers who learned the curriculum in-person vs. online. All online trainings were conducted via Skype, open-source educational videos through YouTube, and one-on-one calls. Virtual training always occurred with students from universities across the United States. Trainers who engaged in watching videos, supplemental readings, and Skype calls were able to implement the program alongside those who had been formally trained through in-person workshops. The variety of training methods further suggests the replicability of the program. If trainers can learn the materials and basic concepts of design-thinking through a variety of structured mediums, then the program model is robust enough to provide the structure needed for variegated methods of learning. However, the exact method of training might be significant based on the different contexts in which the curriculum is being taught. One trainer stated that it is best to use in-person training when implementing the program across multiple sites (i.e., public-school system, YMCA, etc.) Whereas, online training may be a more effective learning method for smaller cohorts of trainers who will all be implementing in one project site together. The flexibility of the Ignite model when it comes to training new educators suggests that it could address issues of scaling curriculum to communities facing a disparity in the quality of coursework available to them (Bishop et al., 2010). Further, community centered learning models such as Ignite have been shown to improve teacher performance and are seen as an important factor even within formal modes of teacher education (Broadly et al., 2019). This suggests the Ignite model might also be useful to incorporate as a case study within university educational departments.

The statistically significant difference between the mean level of positivity toward STEM before and after the implementation of Ignite provides evidence of the effectiveness of the program. Stratifying the results by topic attempts to explore what aspects of Ignite shifted attitudes most significantly. Students also reported the number of STEM classes which they had taken on the survey. The mean number of math classes that they had taken before Ignite, across all students, was 4.95 , the mean number of science classes was 4.68 , but the mean number of technology classes the students reported to have taken before Ignite was only 4.15 and a significantly lower mean of 2.59 engineering classes. It is possible that the increase in STEMpositive scores was due to the novelty of the subjects to the students.

It is to be noted that 11th graders built their projects more autonomously in comparison to other students. This could have contributed to the significant increase in levels of STEM positivity. 7 th, 8 th, and 9 th grade students consulted the trainers about the concepts learned in class more often and also received more help handling materials, such as soldering irons. Although the same curriculum was taught to all grade levels involved, the differential STEM positive reporting could indicate that Ignite is better suited and more effective for older students. A point for further exploration might include an investigation and analysis of the factors that distinguish different cohorts of Ignite trainers/schools (their results, their teaching styles, their circumstances, etc.).

The fact that questions from the engineering and technology section of the Pre- and post- survey had the greatest increase in positive attitudes toward STEM coursework and careers is reflective of the hands-on nature of the course. Before Ignite, IINSS only had science and math courses, but no engineering and technology courses. Though students whose attitudes shifted might still be reluctant to pursue a STEM career, the empowered attitude that the program fostered could still help to cultivate an environment that is more encouraging for students interested in STEM. Future iterations of the program will ensure that appropriate metrics are developed to evaluate critical-thinking, creative problem solving, and increased engagement with key social issues. It is important to note that the student data analyzed in this study was from IINSS where all of the trainers were from Duke University $(n=4)$ and one Guatemalan trainer in the 2018 cohort. The degree to which attitudes improved with Guatemalan university trainers compared with foreign trainers has not been evaluated. Gender may also have an impact, a topic that has not been explored to date. Additionally, different training methods (online vs. in-person) could also affect learning outcomes. In order to ensure quality of instruction, standardized methods need to be developed to allow for flexibility in the training strategy used, while maintaining the rigor needed to maintain high standards of instruction.

Two factors seemed to contribute to the success of Ignite. First, having a community hub-FUNDEGUA—on the ground to continue the program, input resources, and remain close to the communities is essential for the success of Ignite and other novel STEM and design thinking programs. The role of an incountry institutional partner for the sustainability of the program cannot be overstated. Without Ignite being implemented into FUNDEGUA's organizational structure, adapting it for the specific Guatemalan context, it would have not been as successful according to both FUNDEGUA staff and the instructor interviews. Duke trainers simply did not have the capacity, contextual knowledge, and resources to optimize the program in this way. Second, the Ignite model was simple enough to be easily adapted for new settings with new community issues. This seems to be critical for making this program replicable. Imposing a standard formulaic curriculum model would most certainly not have worked in rural schools across Guatemala, some facing extreme drought and others, water pollution. Due to the evolving and iterative nature of the Ignite model from 2017 to 2019 (the scope of this study), developing a robust, accurate, and efficient evaluation and monitoring system is challenging. However, the program has solidified its evaluation strategy for all 19 implementing sites in 2020. The data from this larger impact study will be the subject of a future publication.

\section{DATA AVAILABILITY STATEMENT}

The datasets generated for this study are available on request to the corresponding author. 


\section{ETHICS STATEMENT}

The studies involving human participants were reviewed and approved by Duke University International Review Board. Written informed consent for participation was not provided by the participants' legal guardians/next of kin because: The headmaster (principal) of all participating secondary schools signed a consent waiver for student participation (assent), which was approved through Duke's IRB.

\section{AUTHOR CONTRIBUTIONS}

MD, GA, and NR conceived of the presented idea, developed the theory, and verified the analytical methods. VA completed statistical computations with MT's review. IL conducted in-depth

\section{REFERENCES}

Badura, A. S., Millard, M., Peluso, E. A., and Ortman, N. (2000). Effects of peer education training on peer educators: leadership, self-esteem, health knolwedge, and health behaviors. J. Coll. Stud. Dev. 41, 471-478.

Baines, E., Blatchford, P., and Chowne, A. (2007). Improving the effectiveness of collaborative group work in primary schools: effects on science attainment. Br. Educ. Res. J. 33, 663-680. doi: 10.1080/014119207015 82231

Bishop, R., O'Sullivan, D., and Berryman, M. (2010). Scaling up Education Reform: Addressing the Politics of Disparity. Wellington: New Zealand Council for Educational Research.

Bowling, B., Doyle, M., Taylor, J., and Antes, A. (2015). Professionalizing the role of peer leaders in STEM. J. STEM Educ. 16, 30-39.

Broadly, T., Martin, R., and Curtis, E. (2019). Rethinking professional experience through a learning community model: toward a culture change. Front. Teach. Educ. 4:22. doi: 10.3389/feduc.2019.00022

Carlson, K., Celotta, D. T., Curran, E., Marcus, M., and Loe, M. (2016). Assessing the impact of a multi-disciplinary peer-led-team learning program on undergraduate STEM education. J. Univ. Teach. Learn. Pract. 13, 1-23.

Elayah, M. (2016). Lack of foriegn aid effeciveness in developing countries between a hammer and an anvil. Contemp. Arab Aff. 9, 82-99. doi: 10.1080/17550912.2015.1124519

Freire, P. (2000). Pedagogy of the Oppressed. New York, NY: Continuum International Publishing Group.

Frye, D. (1999). Participatory edcuation as a critical framework for an immigrant women's ESL class. JSTOR 33, 501-513. doi: 10.2307/3587676

Harfitt, G. (2018). The role of the community in teacher preparation: exploring a different pathway to becoming a teacher. Front. Teach. Educ. 3:64. doi: 10.3389/feduc.2018.00064

Martin, P. Y., and Turner, A. B. (1986). Grounded theory and organizational research. J. Appl. Behav. Sci. 22, 141-157. doi: 10.1177/002188638602200207

Mayo, P. (1995). Critical literacy and emancipatoyr politics: the work of Paulo Freire. Int. J. Educ. Dev. 15, 363-379. doi: 10.1016/0738-0593(95)00021-T interviews. All authors discussed the results and contributed to the final manuscript.

\section{FUNDING}

This project has been supported through volunteer efforts and individual research grants (internal to Duke) received by participating Duke undergraduate students.

\section{SUPPLEMENTARY MATERIAL}

The Supplementary Material for this article can be found online at: https://www.frontiersin.org/articles/10.3389/feduc. 2020.00014/full\#supplementary-material

Mueller, J., Peters, J., Dotson, L., Dietzel, J., Asturias, G., Cheatham, A., et al. (2019). Using human-centered design to connect engineering concepts to the sustainable development goals. Adv. Eng. Educ.

Quitadamo, I. J., Brahler, C. J., and Crouch, G. J. (2009). Peer-led team learning: a prospewctive method for increasing critical thinkingh in undergraduate science courses. Phys. Ther. Fac. Publ. 45, 29-39. Available online at: https://ecommons. udayton.edu/dpt_fac_pub/45/

Ruiza-Primo, M., Briggs, D., Iverson, H., Talbot, R., and Shepard, L. (2011). Impact of undergraduate course innovations on learning. Science 331, 1269-1270. doi: 10.1126/science.1198976

Scager, K., Boonstra, J., Peeters, T., Vulperhorst, J., and Wiegant, F. (2016). collaborative learning in higher education: evoking positive interdependence. CBE Life Sci. Educ. 15, 1-9. doi: 10.1187/cbe.16-07-0219

Tenenbaum, L. S., Anderson, M. K., Jett, M., and Yourick, D. L. (2014). An innovative near-peer mentoring model for undergraduate and secondary students: STEM focus. Innovative High. Educ. 39, 375-385. doi: 10.1007/s10755-014-9286-3

UNESCO (2017). Cracking the code girls and womens education in science, technology, engineering and mathematics (STEM). Paris: UNESCO.

Waisbord, S. (2008). The institional challenges of participatory communiciation aid. Social Identities: J. Study Race Nation Cult. 14, 505-522. doi: 10.1080/13504630802212009

Conflict of Interest: The authors declare that the research was conducted in the absence of any commercial or financial relationships that could be construed as a potential conflict of interest.

Copyright (c) 2020 Dotson, Alvarez, Tackett, Asturias, Leon and Ramanujam. This is an open-access article distributed under the terms of the Creative Commons Attribution License (CC BY). The use, distribution or reproduction in other forums is permitted, provided the original author(s) and the copyright owner(s) are credited and that the original publication in this journal is cited, in accordance with accepted academic practice. No use, distribution or reproduction is permitted which does not comply with these terms. 